\title{
An Experimental Investigation of Evaporation Rates for Different Volatile Organic Compounds
}

\author{
Frédéric Heymes, ${ }^{a}$ Laurent Aprin,, ${ }^{a}$ Aurélia Bony, ${ }^{a}$ Serge Forestier, ${ }^{a}$ Stefano Cirocchi,, and \\ Gilles Dusserre ${ }^{a}$ \\ ${ }^{a}$ Institut des Sciences des Risques, Ecole des Mines d'Alès, 6 Avenue de Clavières, 30319 Alès Cedex, France; \\ frederic.heymes@mines-ales.fr (for correspondence) \\ b \\ Department of Chemical Engineering, La Sapienza University, P.le Aldo Moro 5, 00185 Roma, Italy
}

\begin{abstract}
Experiments were performed in order to measure evaporation rates of four different volatile organic compounds (VOC; 2-propanol, 1-hexene, acetone, propanal) and water. Evaporation mass flow rates and liquid temperatures where recorded. Different correlations were tested versus the experimental. Exponents and constant were recalculated to fit the experimental data. This new correlation was tested on an additional VOC experimentation (ethanol) and the accuracy of the correlation was satisfying. The correlation robustness was investi-gated versus temperature and wind velocity.
\end{abstract}

Keywords: evaporation; VOC; volatile organic compound;
spill
INTRODUCTION

Liquid volatile organic compounds (VOC) are frequently used in the chemical industry as reactants, primary products, coatings, solvents, fuels, additives, etc. This type of liquid evaporates quickly and forms vapors with negative effects on people and the environment. Once in a vapor state, these compounds are easily carried out by air movements and can be dispersed over the industrial areas. Numerous works where achieved in the field of liquid evaporation, with a focus on three main concerns: the oil spills on sea or on ground, the liquefied gases spills and the odor emission modeling. More recently, interest in global safety investigated unconventional scenarios.

Oil spills happen frequently due to the large amounts that are pumped and transported around the world [1-5]. Lique-fied gas spills are of interest since LPG and LNG gases are increasingly used. Global safety scenarios may consist in the impact of a projectile on liquid storages. A leak will occur entailing a pool of liquid and therefore evaporation [6,7].

The aim of this work was to perform experiments in order to quantify the evaporation rate of several liquids in wind tunnel conditions. Different wind velocities and five different liquids were investigated. Liquid mass loss and tem-perature were recorded and discussed.

THEORY

When a liquid is spilled on the ground, the open surface of the liquid will enable evaporation due to the imbalance of thermodynamic equilibrium. The pool is characterized by geometrical parameters such as thickness and surface area but also by its temperature and chemical composition. Due to evaporation, the pool temperature and composition will vary depending on heat and mass transfers with the environment. The evaporation of the puddle is a function of different assessments made between the puddle and the environment. In case of pure fluids, it must be noted that evaporation will be regulated by boundary-layer type mass transfer, thus wind is relevant. No mass transfer resistance has to be considered in the liquid since no mass gradient can happen. Brighton [8] investigated these boundary layer effects on pool evaporation. However, the most common theory used to model the mass transfer between the liquid phase and gas phase is the Whitman theory, known also as the "Double Film Model." This theory is described and discussed in previous works [9]. In this work, the mass transfer is only regulated by the film in the gaseous phase. The evaporation flow rate can be written as:

$J=\frac{D_{\mathrm{g}}}{\delta_{\mathrm{g}}} \cdot\left(C_{\mathrm{g}}^{*}-C_{\mathrm{g}}\right)$

where $J$ is the mass flow rate $\left(\mathrm{kg} \mathrm{s}^{-1} \mathrm{~m}^{-2}\right), D_{\mathrm{g}}$ is the diffusivity of the compound in air $\left(\mathrm{m}^{2} \mathrm{~s}^{-1}\right), C_{\mathrm{g}}$ is the concentration of the compound in the air $\left(\mathrm{kg} \mathrm{m}^{-3}\right), C_{\mathrm{g}}^{*}$ is the gas phase equilibrium concentration with the liquid, $\delta_{\mathrm{g}}$ is the thickness of the film on the gas side $(\mathrm{m})$. Using the mass transfer notations, the flow $J$ can be written:

$J=K_{\mathrm{g}} \cdot\left(C_{\mathrm{g}}^{*}-C_{\mathrm{g}}\right)$

where $K_{\mathrm{g}}$ is the mass transfer coefficient in the gas and in the liquid phase, respectively $\left(\mathrm{m} \mathrm{s}^{-1}\right)$. By considering the gas phase as ideal, the following equation can be written:

$C_{\mathrm{g}}^{*}=\frac{P_{\mathrm{v}}(T) \cdot M}{R \cdot T}$

where $P_{\mathrm{v}}(T)$ is the vapor pressure of the compound $(\mathrm{Pa}), T$ is the liquid temperature $(\mathrm{K}), M$ is the molecular weight of the compound $\left(\mathrm{kg} \mathrm{mol}^{-1}\right), R$ is the universal gas constant $=8.31441$ ( $\mathrm{J} \mathrm{mol}^{-1} \mathrm{~K}^{-1}$ ). By coupling Eq. 2 and 3, it can be written: 
Table 1. Comparison of $u, d, D_{\mathrm{g}}$ and $v$ exponents.

\begin{tabular}{lcccc}
\hline Author & Parameter a & Parameter b & Parameter c & Parameter d \\
\hline Raj and Morris & 0.8 & -0.2 & $-1 / 3$ & -0.57 \\
Mackay and Matsugu & 0.78 & -0.11 & $2 / 3$ & -0.67 \\
Green and Maloney & 0.5 & -0.5 & $-1 / 3$ & -0.17 \\
This work & 0.69 & -0.31 & 0.13 & -0.18 \\
\hline
\end{tabular}

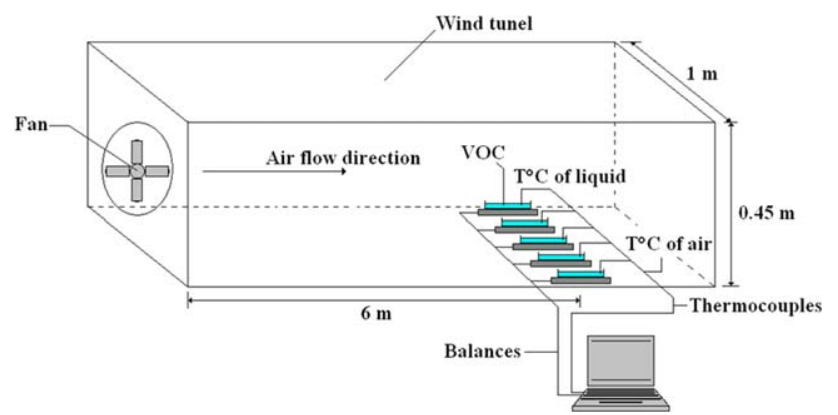

Figure 1. Diagram of the experimental set-up. [Color figure can be viewed in the online issue, which is available at wileyonlinelibrary.com.]

$J=K_{\mathrm{G}} \frac{P_{\mathrm{V}}(T) \cdot M}{R \cdot T}$

The evaporation of the species will provoke a decrease of the liquid temperature since vaporization is endothermic and will consume vaporization enthalpy $\Delta H_{\text {vap }}$. The enthalpy balance will result from endothermic phase change and heat transfers by convection with air, conduction with ground and radiative fluxes (sun, atmosphere). The mass balance equation has to be completed by a heat balance:

$$
\left\{\begin{array}{l}
J=-\rho_{\mathrm{L}} \frac{d(b)}{d t}=K_{\mathrm{g}} \cdot \frac{P_{\mathrm{v}}\left(T_{\mathrm{L}}\right) \cdot M}{R \cdot T} \\
b \cdot \rho_{\mathrm{L}} \frac{d\left(C_{\mathrm{P}, \mathrm{L}} T_{\mathrm{L}}\right)}{d t}=\varphi_{\text {ground }}+\varphi_{\text {air }}+\varphi_{\mathrm{atm}}+\varphi_{\text {sun }}+J \cdot \Delta H_{\mathrm{vap}}
\end{array}\right.
$$

where $h$ is the liquid thickness $(\mathrm{m}), \rho_{\mathrm{L}}$ is the liquid density $\left(\mathrm{kg} \mathrm{m} \mathrm{m}^{-3}\right), \Delta H_{\text {vap }}$ the vaporization enthalpy (negative) (J $\left.\mathrm{kg}^{-1}\right), C_{\mathrm{p}, \mathrm{L}}$ is the heat capacity of the liquid $\left(\mathrm{J} \mathrm{kg}^{-1} \mathrm{~K}^{-1}\right)$, $\varphi_{\text {ground, }}, \varphi_{\text {air }}, \varphi_{\text {atm }}, \varphi_{\text {sun }}$ are the heat fluxes with the ground $\left(\mathrm{W} \mathrm{m}^{-2}\right.$ ), the air, the atmosphere, and the sun. The main work was achieved in order to evaluate $K_{\mathrm{g}}$ in regard with the air velocity and the VOC identity. The mass transfer coefficient in air $K_{\mathrm{g}}$ depends on the velocity of the wind $u_{\text {air }}$, the air density $\rho_{\text {air }}$, the air dynamic viscosity $\mu_{\text {air }}$, the diameter of the evaporation pool $d$, and the compound diffusivity $D_{\mathrm{g}}$. A dimensional analysis allows correlating $K_{\mathrm{g}}$ with $u_{\text {air }}, \rho_{\text {air }}, \mu_{\text {air }}$, $d$, and $D_{\mathrm{g}}$ by the classic equation $S b=f(R e, S c)$, where $S b$ is the Sherwood number, $S c$ is the Schmidt number, Re is the Reynolds number.

$S c=\frac{\mu_{\text {air }}}{\rho_{\text {air }} \cdot D_{\mathrm{g}}} \quad R e=\frac{\rho_{\text {air }} \cdot u_{\text {air }} \cdot d}{\mu_{\text {air }}} \quad S h=\frac{K_{\mathrm{m}} \cdot d}{D_{\mathrm{g}}}$

A key point in determining the Reynolds number is the definition of the wind velocity $u_{\text {air }}$. Indeed, the velocity profile of incoming wind depends strongly on the atmospheric
Table 2. Geometrical parameters of the experimentations.

\begin{tabular}{lc}
\hline Parameter & Dimension \\
\hline $\begin{array}{l}\text { VOC pool dimensions } \\
\quad \text { (Length } \times \text { Width } \times \text { Depth), cm }\end{array}$ & $22.8 \times 19.00 \times 1.50$ \\
Wind tunnel dimensions \\
$\quad($ Length $\times$ Width $\times$ Depth), m \\
VOC pool position in the \\
$\quad$ wind tunnel from the fan, $\mathrm{m}$ \\
VOC quantity in the pool, mL
\end{tabular}

boundary layer, atmospheric stability, ground roughness, and local configuration such as the presence of obstacles or bunds. Therefore, different definitions of the wind velocity can be used: at 10 meters high, at the edge of the pool or can be averaged over a height.

The function $f(R e, S c)$ was evaluated from experimental data by Raj and Morris [10], Mackay [4], and Green [11]. It is interesting to compare the value of exponents. For that, the equations were rewritten as:

$$
K_{\mathrm{G}}=f\left(u^{\mathrm{a}}, d^{\mathrm{b}}, D_{\mathrm{g}}^{\mathrm{c}}, v^{\mathrm{d}}\right)
$$

Thus, the proposed relationship evolves differently according to each of the different parameters (Table 1). The formula from Green and Maloney takes into account wind velocity less than others. The diameter of the pool is taken into account in very dissimilar from model to model. The gap is even more notable for diffusivity. Indeed, according to Ref. 4, increased diffusivity promotes the coefficient of mass transfer on the contrary for the other two formulas; the mass transfer is a function of decreasing diffusivity. These differences show how evaporation modeling is still not well understood. Boundary layer hydrodynamics conditions vary strongly depending on the experimental conditions and could explain these differences.

\section{EXPERIMENTAL SETUP}

A simplified scheme of the experimental set-up with a wind tunnel and five liquid pools is presented in Figure 1. In every pool (material: polypropylene), the evaporation of the liquid is recorded by a digital balance (OHAUS brand). The liquid and air temperature were measured by $\mathrm{K}$ type thermocouples (diameter $0.25 \mathrm{~mm}$ ) and recorded in real time. It has to be noted that, for each test, the velocity of the wind was measured at $15 \mathrm{~cm}$ above the pool (KIMO VT 200 hotwire), in the constant velocity profile corresponding to turbulent flow. No turbulence measurement was performed. In order to have the same operating parameters, five pools were tested simultaneously with the five liquids. Experimental air velocities where chosen is the range $[1.6-4] \mathrm{m} \mathrm{s}^{-1}$. The setup parameters of the experimentation are presented in Table 2 . 


\section{RESULTS AND DISCUSSION}

\section{Experimental Results}

The first experimental setup is about the mass variations for the tested liquids (2-propanol, 1-hexene, acetone, propanal, and water) under a constant wind of $3.20 \mathrm{~m} \mathrm{~s}^{-1}$. Results are presented in Figures 2 and 3. The first period corresponds to the time necessary to have a constant wind velocity and to fulfill the pools. For each liquid, there is a transition period after filling during which the mass transfer in air is more intense than during the rest of the evaporation process. This is due to initial liquid temperature decrease which lowers the vapor pressure of the component and

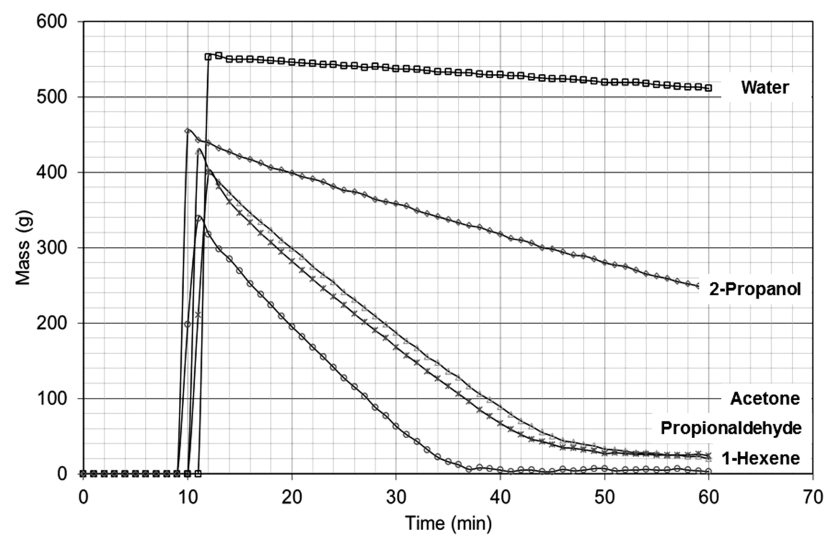

Figure 2. Evaporation rate of water, propanol, acetone, propionaldehyde, and hexene $\left(u=3.2 \mathrm{~m} \mathrm{~s}^{-1}\right)$.

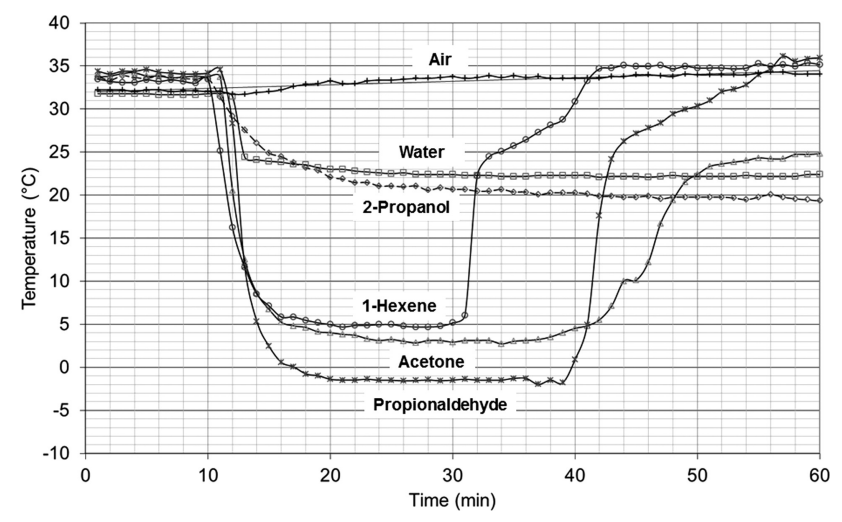

Figure 3. Air and liquid temperature during evaporation rate at constant wind velocities $\left(u=3.2 \mathrm{~m} \mathrm{~s}^{-1}\right)$. thereby reduces the evaporation rate. The temperature drop is due to the heat imbalance of the system: the heat sink due to evaporation enthalpy is not balanced by heat exchange with the air, the ground, and the solar intake and liquid temperature decreases. This temperature decrease is presented on Figure 3. After a while, corresponding to 8 minutes for hexane, 13 minutes for water and acetone and 40 minutes for propanol, the temperature is stable, and therefore, the evaporation rate becomes constant.

These results enable to calculate mass transfer constant $K_{\mathrm{G}}$, given in Table 3 . The vapor pressures were calculated at the surface temperature which was assumed to be equal to the liquid temperature. The vapor diffusivities were calculated at an average temperature between liquid and air temperatures. The calculated values of Schmidt and Sherwood numbers obtained from the experimental data for the five tested compounds are presented in Table 4.

The second experimental set is about the evaporation rate of acetone with different wind velocities from 1.6 to $4.0 \mathrm{~m}$ $\mathrm{s}^{-1}$. Results are reported in Table 5. Mass losses of acetone versus time for different wind velocities were reported on Figure 4 and temperatures are reported on Figure 5. As expected, an increase in wind velocity entails a higher evaporation rate. It can be noticed that the liquid temperature during the continuous evaporation regime is constant and approximately, the same for all experiments. If the liquid temperature is constant, Eq. 5 can be written as following:

$\varphi_{\text {ground }}+\varphi_{\text {air }}+\varphi_{\text {atm }}+\varphi_{\text {sun }}=-J \cdot \Delta H_{\text {vap }}$

Considering that liquid temperature was constant whatever the wind velocity, only the heat convection between air and liquid will depend on the velocity. Therefore,

$\varphi_{\text {atm }}=K_{\text {th }}\left(T_{\text {air }}-T_{\text {liquid }}\right)=-K_{\mathrm{g}} \cdot \frac{P_{\mathrm{v}}\left(T_{\mathrm{L}}\right) \cdot M}{R \cdot T} \cdot \Delta H_{\text {vap }}+$ constant

where $K_{\mathrm{th}}$ is the heat transfer constant of convection between air and liquid $\left(\mathrm{J} \mathrm{m}^{-2} \mathrm{~K}^{-1} \mathrm{~s}^{-1}\right)$. Temperature

Table 4. Schmidt, Reynolds, and Sherwood numbers of the first experimental set.

\begin{tabular}{llll}
\hline Compound & $S c_{\exp }$ & $S h_{\exp }$ & $R e_{\exp }$ \\
\hline Water & 6.46 & 1,368 & 51,798 \\
2-Propanol & 15.89 & 2,697 & 51,798 \\
Acetone & 16.30 & 3,166 & 51,798 \\
Propanal & 16.48 & 2,814 & 51,798 \\
1-Hexene & 21.99 & 4,149 & 51,798
\end{tabular}

Table 3. Physical properties and mass transfer constants (first set).

\begin{tabular}{|c|c|c|c|c|c|}
\hline Parameter & 2-Propanol & 1-Hexene & Acetone & Propanal & Water \\
\hline Vapour diffusivity ${ }^{* *}, \mathrm{~cm}^{2} \mathrm{~s}^{-1}$ & $1.03 \times 10^{-2}$ & $7.43 \times 10^{-3}$ & $1.00 \times 10^{-2}$ & 9. $\times 10^{-3}$ & $2.53 \times 10^{-2}$ \\
\hline Vapour pressure, $\mathrm{Pa}$ & 4,449 & 9,985 & 11,151 & 12,521 & 2,729 \\
\hline Mass flow, $\mathrm{g} \cdot \mathrm{cm}^{-2} \mathrm{~s}^{-1}$ & 1.16 & 4.26 & 3.41 & 3.42 & 0.26 \\
\hline Mass transfer coefficient ${ }^{* *} K_{\mathrm{G}} \mathrm{m} \mathrm{s}^{-1}$ & $1.06 \times 10^{-2}$ & $1.17 \times 10^{-2}$ & $1.21 \times 10^{-2}$ & $1.06 \times 10^{-2}$ & $1.32 \times 10^{-2}$ \\
\hline
\end{tabular}

*measured values.

**alculated values. 
Table 5. Physical properties and mass transfer constants at different wind velocities (second set).

\begin{tabular}{|c|c|c|c|c|c|}
\hline \multirow[b]{2}{*}{ Parameter } & \multicolumn{5}{|c|}{ Wind Velocity $\left(\mathrm{m} \mathrm{s}^{-1}\right)$} \\
\hline & 1.6 & 2.0 & 2.4 & 3.2 & 4.0 \\
\hline Average air temperature ${ }^{*}, \mathrm{~K}$ & 305.44 & 309.98 & 302.63 & 305.43 & 307.55 \\
\hline Liquid average temperature", $\mathrm{K}$ & 278.62 & 279.24 & 277.91 & 277.19 & 277.85 \\
\hline Vapour diffusivity ${ }^{* * *}, \mathrm{~cm}^{2} \mathrm{~s}^{-1}$ & $1.01 \mathrm{E}-02$ & $1.02 \mathrm{E}-02$ & $9.95 \mathrm{E}-03$ & $1.00 \mathrm{E}-02$ & $1.01 \mathrm{E}-02$ \\
\hline Vapour pressure $^{*}, \mathrm{kPa}$ & 12,432 & 12,823 & 11,996 & 11,567 & 11,960 \\
\hline Kinematic air viscosity ${ }^{* *}, \mathrm{~cm}^{2} \mathrm{~s}^{-1}$ & 0.162 & 0.166 & 0.160 & 0.162 & 0.164 \\
\hline Mass flow ${ }^{*} \mathrm{~g} \mathrm{~m}^{-2} \mathrm{~s}^{-1}$ & 1.98 & 2.34 & 2.53 & 3.02 & 3.51 \\
\hline Mass transfer coefficient ${ }^{* *}, \mathrm{~m} \mathrm{~s}^{-1}$ & $0.64 \times 10^{-2}$ & $0.73 \times 10^{-2}$ & $0.84 \times 10^{-2}$ & $1.04 \times 10^{-2}$ & $1.17 \times 10^{-2}$ \\
\hline
\end{tabular}

*measured values.

**alculated values.

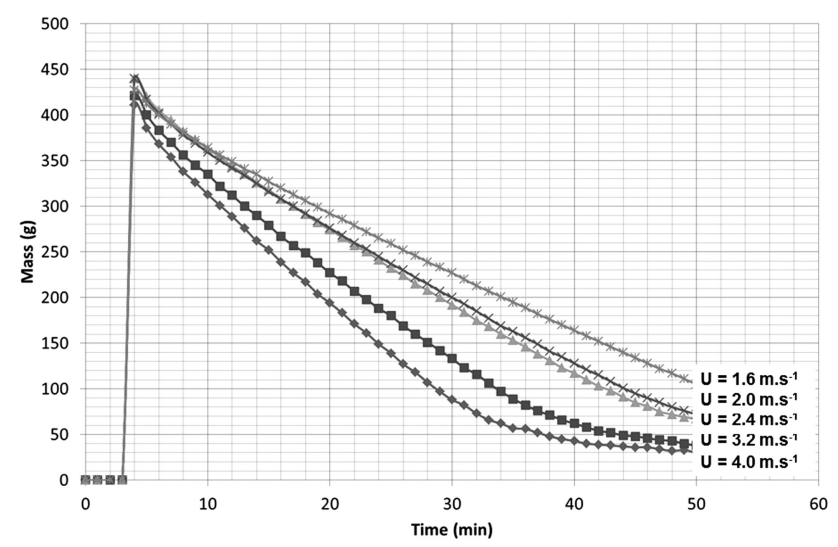

Figure 4. Evaporation rate of acetone at different wind velocities.

difference between both phases were calculated and reported on Figure 6. A good agreement between heat and mass transfer coefficient was observed (Figure 7), confirming the heat-mass transfers analogy.

The calculated values of Reynolds and Sherwood numbers obtained from the experimental data at different wind velocities for acetone are presented in Table 6.

\section{Mass Transfer Modeling}

Correlations of Raj and Morris, Mackay and Matsugu, Green and Maloney were tested with the experimental data and poor accuracy was observed (average absolute relative error [AARE] higher than 90\%).Since the liquid temperature was measured and not calculated, this low accuracy is only due to the mass transfer coefficient modeling inaccuracy. While considering the experimental conditions of the previous works, differences appear on the wind production and measurement. Indeed, the air movement was created by natural wind, a fan or a wind tunnel. Air velocity was measured in situ or 10 meters above the ground. This entails that the comparison of correlation accuracy is unwise and shows that no unique modeling is available at this time. If one considers wind velocity at 10 meters above the liquid, the Mackay and Matsugu should be used. If a more detailed wind velocity calculation is undertaken (e.g., computational fluid dynamics), a new correlation is proposed with a local wind (out of boundary layer). A mathematical regression of data aiming to get exponents and constant of the $f$ function leads to the following equation:

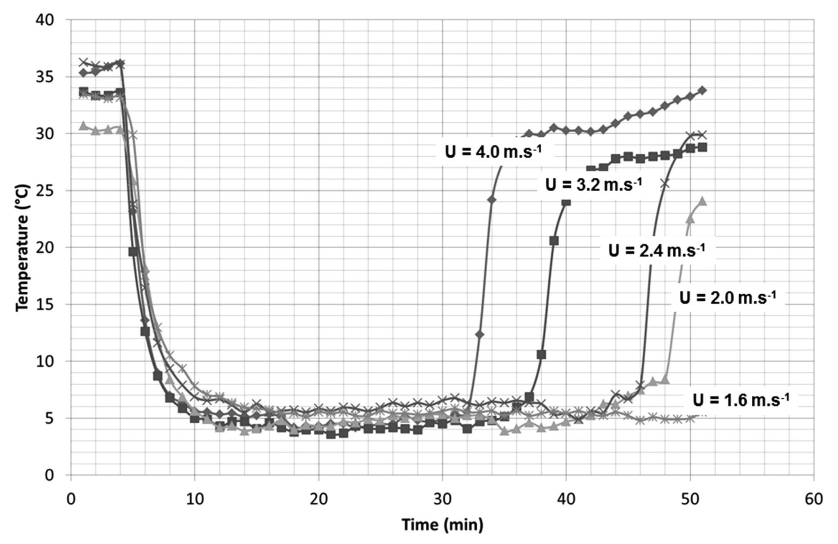

Figure 5. Liquid temperatures during evaporation rate of acetone at different wind velocities.

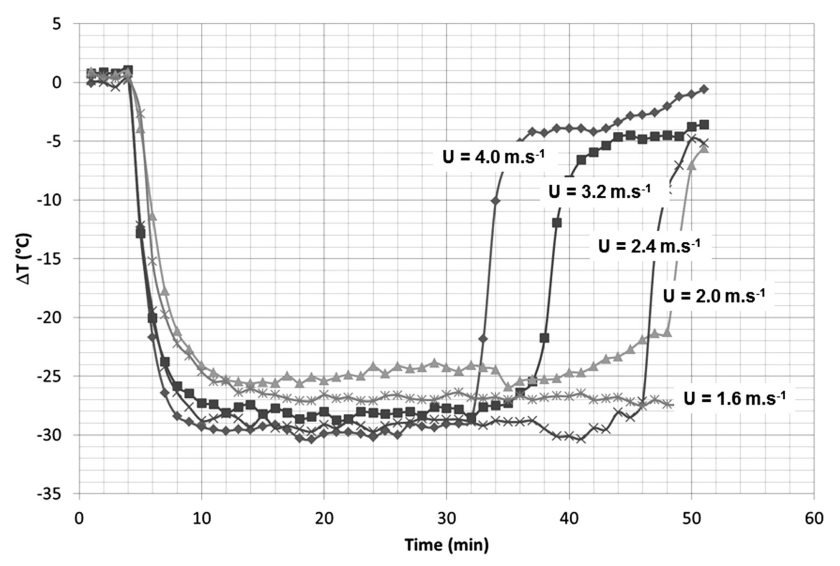

Figure 6. Temperature difference between liquid and air.

$S h=0.145 \cdot R e^{0.69} \cdot S c^{0.87}$

Replacing the Sherwood number the mass transfer coefficient $K_{\mathrm{g}}$ can be expressed as:

$K_{\mathrm{g}}=0.145 \cdot u^{0.69} \cdot d^{-0.31} \cdot D^{0.13} v^{-0.18}$

The exponents differ with previous exponents presented in the theoretical part. This shows how different operating 
conditions lead to different mathematical regressions. The AARE on the proposed correlation was taken into consideration for the stationary conditions. This error was expressed as an average of the relative errors calculated between the theoretical and experimental Sherwood numbers with additional experiments. The AARE percentage can be estimated at approximately $6.9 \%$ (Table 7 ).

Since a low AARE is obvious because the regression was achieved on the kind of VOCs and wind range employed for it, it was decided to test the correlation on an additional VOC. Ethanol was chosen in order to perform this test. A very good agreement was found and confirm the validity of this relationship for VOC evaporation rate with a wind lower than $4 \mathrm{~m} \mathrm{~s}^{-1}$.

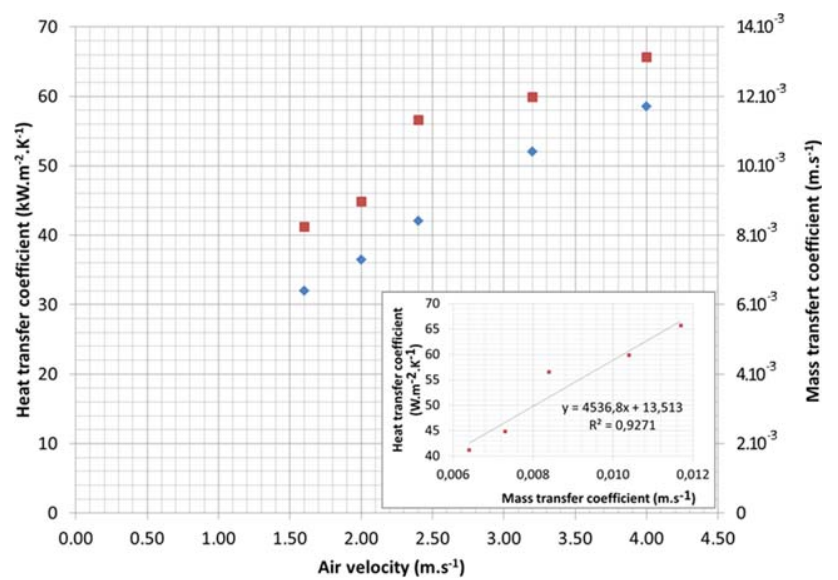

Figure 7. Comparison of heat and mass transfer constants. [Color figure can be viewed in the online issue, which is available at wileyonlinelibrary.com.]

Table 6. Reynolds, Schmidt, and Sherwood numbers based on experimental data of the second set.

\begin{tabular}{llll}
\hline Wind velocity $\left(\mathrm{m} \mathrm{s}^{-1}\right)$ & $R e_{\exp }$ & $S c_{\exp }$ & $S h_{\exp }$ \\
\hline 1.60 & 25,898 & 16.30 & 1659 \\
2.00 & 31,546 & 16.30 & 1872 \\
2.40 & 39,479 & 16.30 & 2210 \\
3.20 & 51,798 & 16.30 & 2717 \\
4.00 & 63,969 & 16.30 & 3040 \\
\hline
\end{tabular}

\section{Robustness of the New Correlation}

Given that heat and mass balance equations are linked, a wrong estimation of the evaporation rate or liquid temperature leads to wrong estimations of these parameters at further steps in the calculation. This section presents the robustness of the new correlation, that is, the error induced on the evaporation rate calculation if a misestimated liquid temperature or wind velocity is employed. This point it realized thanks to local sensitivity analysis. The statistical index (Eq. 10) employed consists to freeze every parameter but one and to analyze the correlation result.

$S_{X_{i}}=\frac{\frac{\partial f\left(X_{1}, \ldots, X_{p}\right)}{\partial X_{i}}}{f\left(X_{1}, \ldots, X_{p}\right)} \times 100$

This index directly presents the error induced on the correlation's result $\left(S_{X i}\right.$ in \% per unit of $\left.X_{i}\right)$ by the $i^{\text {th }}$ parameter in percentage per unit of $i^{\text {th }}$ parameter. The shift between the real evaporation rate and the estimated one is the integral of Eq. 10 between the parameter's value employed and its real one. The new correlation and the Mackay's one are a polynomial function strictly positive on the studied area. Both conditions are met.

The preceding method does not directly allow visualizing the error induced as a function of a given value of the different parameters. A second index is built (Eq. 11) that expresses the shift between the result of a correlation and the real evaporation rate $\left(\Phi_{0}\right)$.

$S_{X_{i}}=\frac{\left|f\left(X_{1}, \ldots, X_{p}\right)-\Phi_{0}\right|}{f\left(X_{1}, \ldots, X_{p}\right)} \times 100$

Liquid Temperature Influence

Wrong estimations of the liquid temperature may come from a bad estimation of one of the two balance equations. It appears that:

- The error induced by the Mackay and Matsugu equation is low (below $0.17 \% . \mathrm{K}^{-1}$ ) but the new one is eight times lower. It means that this new correlation does nearly not imply any deviation induced by temperature. In that sense, the only error on the evaporation rate lies in the computation of the surface concentration.

- The error decreases with liquid temperature.

In order to get the error induced around a given temperature, Eq. 11 is used. It is then possible to know the error induced on the evaporation rate as a function of the uncertainty of the liquid temperature. Such as predicted by

Table 7. EARM between the theoretical and experimental Sherwood numbers.

\begin{tabular}{lcccccc}
\hline Liquid & Wind Velocity $\left(\mathrm{m} \mathrm{s}^{-1}\right)$ & $R e$ & $S c$ & $S h_{\text {Theor }}$ & $S h_{\text {exp }}$ & Relative Error $(\%)$ \\
\hline Water & 3.20 & 51,450 & 6.46 & 2,796 & 2,697 & 3.67 \\
2-Propanol & 3.20 & 51,450 & 15.89 & 3,708 & 4,149 & 10.64 \\
Acetone & 3.20 & 51,450 & 16.30 & 2,858 & 3,166 & 9.76 \\
Propanal & 3.20 & 51,450 & 16.48 & 2,886 & 2,814 & 2.56 \\
1-Hexene & 3.20 & 51,450 & 21.99 & 1,279 & 1,368 & 6.55 \\
Acetone & 1.60 & 25,898 & 16.30 & 1,767 & 1,659 & 6.46 \\
Acetone & 2.00 & 31,547 & 16.30 & 2,042 & 1,872 & 9.05 \\
Acetone & 2.40 & 39,480 & 16.30 & 2,340 & 2,211 & 5.85 \\
Acetone & 31,799 & 16.30 & 2,858 & 2,718 & 5.15 \\
Acetone & 3.20 & 63,969 & 16.30 & 3,315 & 3,040 & AARE
\end{tabular}


the former figure, the error induced by the new correlation is much lower than the one induced by Mackay and Matsugu correlation.

It appears that every correlation has the same shape:

- The evaporation rate is underestimated if the estimated temperature is lower than the real one.

- The evaporation rate is overestimated if the estimated temperature is higher than the real one.

This error distribution allows some mathematical stability. Indeed, in case of overestimation of the liquid temperature, the evaporation rate is overestimated and then leads to a lower estimated temperature at the next calculation step and thus a lower evaporation rate.

\section{Wind Velocity Influence}

The errors on related to wind velocity impacts two parameters

- The convective heat flux exchanged between the air and the liquid.

- The mass transfer coefficient that drives evaporation.

For the two correlations, the error reaches more than $100 \%\left(\mathrm{~m} \mathrm{~s}^{-1}\right)^{-1}$ and the error decreases strongly when the wind velocity increases. It is interesting to notice that the error distribution is strongly different according to the wind velocity. In case of wind velocity (above $2 \mathrm{~m} \mathrm{~s}^{-1}$ ), the error induced is low (below 20\% $\left.\left(\mathrm{m} \mathrm{s}^{-1}\right)^{-1}\right)$. For lower wind velocities, the error can reach more than $100 \%$ of the evaporation rate.

However, it appears that the new correlation is less sensitive to wind error for wind velocities above $1 \mathrm{~m} \mathrm{~s}^{-1}$ which is a common value outside. If the computation focus on $4 \mathrm{~m}$ $\mathrm{s}^{-1}$ (that is the wind velocity during the experiment, the results confirm the observations of the last figure. The influences of the wind are less significant when the new correlation is employed.

\section{CONCLUSION}

Two different sets of experiments were performed in order to assess VOC evaporation. It was shown that evaporation entails a strong decrease in temperature and that a stationary behavior happens after a time depending on the chemical properties of the liquid. Evaporation prediction tools should be employed with that lower liquid temperature in order to ameliorate the prediction accuracy.

On a modeling consideration, no existing correlation fitted accurately to the experimental data. This is mainly due to the fact that previous correlations were established in different experimental parameters and cannot be employed in the present experiments. A work should be done on a large set of experimental data (including this work) in order to fit the dimensionless correlation $f(R e, S c)$ on various configurations.

A sensitivity analysis has been conducted to check if the new correlation is more robust than the Mackay and Matsugu correlation. It appears that the sensitivity linked with liquid temperature has drastically been reduced while the one due to wind velocity is reduced when the flow speed is higher than $1 \mathrm{~m} \mathrm{~s}^{-1}$. In that sense, the new correlation is an enhancement of the former models.

\section{NOMENCLATURE}

$C_{\mathrm{g}}$ Concentration of the compound in the gas phase ( $\mathrm{g}$ $\mathrm{cm}^{-3}$ )

$C_{\mathrm{g}}^{*} \quad$ Equilibrium concentration of the compound in the gas phase at the interface $\left(\mathrm{g} \mathrm{cm}^{-3}\right)$

$D_{\mathrm{g}} \quad$ Diffusivity of the compound in the gas phase $\left(\mathrm{cm}^{2}\right.$ $\mathrm{s}^{-1}$ )

$\delta_{\mathrm{g}} \quad$ Thickness of the gas film $(\mathrm{cm})$

$d_{\mathrm{eq}} \quad$ Diameter equivalent of the pool $(\mathrm{cm})$

$\rho_{\text {air }} \quad$ Air density $\left(\mathrm{g} \mathrm{cm}^{-3}\right)$

$J \quad$ Mass flow of the compound at interface $\left(\mathrm{g} \mathrm{cm}^{-2} \mathrm{~s}^{-1}\right)$

$K_{\mathrm{g}} \quad$ Mass transfer coefficient in the gas phase $\left(\mathrm{cm} \mathrm{s}^{-1}\right)$

$K_{\mathrm{th}} \quad$ Convective heat transfer coefficient $\left(\mathrm{J} \mathrm{m}^{-2} \mathrm{~K}^{-1} \mathrm{~s}^{-1}\right)$

$M \quad$ Molecular weight of the compound $\left(\mathrm{g} \mathrm{mol}^{-1}\right)$

$M_{\text {air }} \quad$ Air molecular weight $\left(\mathrm{g} \mathrm{mol}^{-1}\right)$

$P_{\mathrm{v}} \quad$ Vapour pressure of the compound at interface $(\mathrm{Pa})$

$R \quad$ Universal gas constant $\left(\mathrm{J} \mathrm{mol}^{-1} \mathrm{~K}^{-1}\right)$

Re Reynolds number

Sc Schmidt number

Sh Sherwood number

$T_{\text {air }} \quad$ Air temperature (K)

\section{LITERATURE CITED}

1. M. Fingas, A literature review of the physics and predictive modelling of oil spill evaporation, J Hazard Mater 42 (1995), 157-175.

2. M. F. Fingas, Modelling evaporation using models that are not boundary-layer regulated, J Hazard Mater 107 (2004), 27-36.

3. W. Stiver and D. Mackay, Evaporation rate of spills of hydrocarbons and petroleum mixtures, Environ Sci Technol 18 (1984), 834-840.

4. D. Mackay and R.S. Matsugu, Evaporation rates of liquid hydrocarbon spills on land and water, Can J Chem Eng 51 (1973), 434-439.

5. P.J. Leinonen and D. Mackay, A mathematical model of evaporation and dissolution from oil spills on ice, land, water and under ice, Water Pollution Research, Canada, 1975,132-141.

6. N. Lecysyn, A. Dandrieux, F. Heymes, P. Slangen, L. Munier, L. Lapebie, C. Le Gallic, and G. Dusserre, Preliminary study of ballistic impact on an industrial tank: Projectile velocity decay, J Loss Prevention Process Ind 21 (2008), 627-634.

7. N. Lecysyn, A. Dandrieux, F. Heymes, L. Aprin, P. Slangen, L. Munier ,C. Le Gallic, and G. Dusserre, Ballistic impact on an industrial tank: Study and modeling of consequences, J Hazard Mater 172 (2009), 587-594.

8. P.W.M. Brighton, Further verification of a theory for mass and heat transfer from evaporating pools, J Hazard Mater 23 (1990), 215-234.

9. R.L. Smith, Predicting evaporation rates and times spills of chemical mixtures, Ann Occupat Hygiene 6 (2001), 437-445.

10. TNO, 1997, Chapter 3 Pool Evaporation, Method for the calculation of physical effects Part 1

11. D.W. Green and J.O. Maloney, Perry's Chemical Engineer's Handbook, 7th Ed., McGraw-Hill, New York, 1997. 